IZA DP No. 6043

Culture, Intermarriage, and Differentials in Second-Generation Immigrant Women's Labor Supply

Z. Eylem Gevrek Deniz Gevrek Sonam Gupta

October 2011 


\title{
Culture, Intermarriage, and Differentials in Second-Generation Immigrant Women's Labor Supply
}

\author{
Z. Eylem Gevrek \\ University of Konstanz \\ Deniz Gevrek \\ Texas A\&M University-Corpus Christi \\ and IZA \\ Sonam Gupta \\ University of Florida
}

\section{Discussion Paper No. 6043 \\ October 2011}

\author{
IZA \\ P.O. Box 7240 \\ 53072 Bonn \\ Germany
}

Phone: +49-228-3894-0
Fax: +49-228-3894-180
E-mail: iza@iza.org

Any opinions expressed here are those of the author(s) and not those of IZA. Research published in this series may include views on policy, but the institute itself takes no institutional policy positions.

The Institute for the Study of Labor (IZA) in Bonn is a local and virtual international research center and a place of communication between science, politics and business. IZA is an independent nonprofit organization supported by Deutsche Post Foundation. The center is associated with the University of Bonn and offers a stimulating research environment through its international network, workshops and conferences, data service, project support, research visits and doctoral program. IZA engages in (i) original and internationally competitive research in all fields of labor economics, (ii) development of policy concepts, and (iii) dissemination of research results and concepts to the interested public.

IZA Discussion Papers often represent preliminary work and are circulated to encourage discussion. Citation of such a paper should account for its provisional character. A revised version may be available directly from the author. 
IZA Discussion Paper No. 6043

October 2011

\section{ABSTRACT \\ Culture, Intermarriage, and Differentials in Second-Generation Immigrant Women's Labor Supply}

We examine the impact of culture on the work behavior of second-generation immigrant women in Canada. We contribute to the current literature by analyzing the role of intermarriage in intergenerational transmission of culture and its subsequent effect on labor market outcomes. Using relative female labor force participation and total fertility rates in the country of ancestry as cultural proxies, we find that culture matters for the female labor supply. Cultural proxies are significant in explaining number of hours worked by secondgeneration women with immigrant parents. More importantly, we show that the impact of cultural proxies is significantly larger for women with immigrant parents who share same ethnic background than for those with intermarried parents. The fact that the effect of culture is weaker for women who were raised in intermarried families stresses the importance of intermarriage in assimilation process. Our results are robust to different specifications and estimation strategies.

JEL Classification: J12, J16, J22, J61

Keywords: culture, labor supply, immigrant women, intermarriage

Corresponding author:

Z. Eylem Gevrek

Department of Economics

University of Konstanz

P.O. Box 137

78457 Konstanz

Germany

E-mail: zahide.gevrek@konstanz-uni.de 


\section{Introduction}

Female labor force participation varies substantially across countries. ${ }^{1}$ What can explain these large differences? Existing literature stresses the importance of differences in human capital, economic conditions, institutions, and cultural norms. The latter represent views about women's roles in society, ideal family size, and the education of women, which vary systematically across countries. Cross-country studies attempt to isolate the effect of culture from economic and institutional factors by controlling for differences in the economic environment of the country of origin and by identifying the residual with culture. However, these studies suffer from omitted variable and endogeneity problems due to the difficulty of summarizing the economic environment faced by agents with a few aggregate variables (Fernández 2008).

The recent research on the role of culture in explaining variation in economic outcomes focuses on immigrants within a single country and uses home country variables to separate the effects of culture from those of economic variables and institutions. Fernández and Fogli (2006, 2009) use past values of female labor force participation and total fertility rates from the woman's country of ancestry as cultural proxies to study the impact of culture on work and fertility behavior of second-generation immigrant women in the U.S. They show that culture plays an important role in the determination of those two outcomes. Carroll et al. (1994) investigate the effect of culture on savings behavior of first-generation immigrants in Canada. Using data from the Canadian Survey of Family Expenditures, they do not find a significant effect of culture on saving patterns of immigrants. However, the authors point out that their conclusions must be viewed as tentative due to data limitations arising from non-availability of information on the country of origin and poor measures of wealth. ${ }^{2}$

\footnotetext{
${ }^{1}$ Female labor force participation rate in 2008 in OECD countries ranges from $27.4 \%$ in Turkey to $85.4 \%$ in Iceland.

${ }^{2}$ The authors are able to identify immigrants by the region of origin rather than country of origin due to data limitations. The data set used in their empirical analysis divides immigrants' countries of origin into the following regions: North and West Europe (with the United States), South and East Europe, China and Southeast Asia, Other Asia and Other Countries.
} 
Alesina and Giuliano (2010) examine the importance of culture, as measured by the strength of family ties, on economic outcomes among second-generation immigrants in the U.S. They construct their cultural proxy using individual responses from the World Value Survey of the role of family and the need for love and respect from children toward their parents for over 70 countries. Their results indicate that strong family ties are associated with more home production of goods and services and less labor market participation for women. Using home country variables as a measure of culture, Antecol (2001) studies the effect of cultural factors on variation in the gender wage gap among immigrants in the U.S. The author finds that there exists a positive correlation between variation in the gender wage gap of first generation immigrants in the U.S. and the corresponding variations in the home country gender wage gap, indicating the importance of cultural factors. ${ }^{3}$

Our paper is related to a growing literature on the impact of culture on economic outcomes. We examine the role of culture in the work behavior of second-generation immigrant women in Canada. ${ }^{4}$ We contribute to this literature by stressing the importance of intermarriage in intergenerational transmission of culture. There is a large sociological literature that considers intermarriage as the crucial sign of behavioral and cultural assimilation (Gordon 1964; Pagnini and Morgan 1990; Qian 1999; Qian and Lichter 2001). To the best of our knowledge, however, this study is the first that empirically examines the role of intermarriage in intergenerational cultural transmission.

Analyzing the role of marriage in the development of cultural traits of children, Bisin and Verdier (2000) argue that each individual's choice of spouse plays an important role in her/his ability to transmit his/her set of cultural traits to any eventual children. The interaction of the direct socialization efforts of parents, such as spending time with children or choosing appropriate neighborhoods and acquaintances, and the indirect influence of

\footnotetext{
${ }^{3}$ See Fernández (2010) for a review of the studies that use immigrants to examine the impact of culture on a variety of outcomes such as female labor force participation, fertility, growth, redistribution and living arrangements. Guiso et al. (2006) also provide a thorough review of literature that investigates both theoretically and empirically the effect of culture on economic outcomes.

${ }^{4}$ Second-generation Canadians are defined as individuals born in Canada with at least one foreign-born parent.
} 
society toward assimilation determine the effective socialization of children to a particular ethnic trait. Families in which parents share the same cultural traits have a more efficient socialization technology for their shared trait while families with mixed cultural parents may have difficulty passing on a consistent ethnic culture to their children as the spouse favors a different set of traits and peers and role models are usually chosen from the population at large. In line with the economic analysis of the intergenerational transmission of ethnic traits through family socialization and marriage in Bisin and Verdier (2000), we hypothesize that the impact of the cultural proxies is stronger for women who have two foreign-born parents with the same ethnic background than for those with one foreign-born parent, as children of intermarried parents are culturally more assimilated than children of immigrant parents. ${ }^{5}$

Second-generation immigrants born and raised in Canada share the same markets and institutions; however, they potentially differ in their cultural heritage. To isolate the effects of culture from those due to strictly economic factors and institutions, we use female labor force participation rate (hereafter LFPR) relative to male LFPR and total fertility rate (TFR) in the country of ancestry as our cultural proxies. ${ }^{6}$ Those measures should depend on economic conditions, institutions and cultural norms in the country of ancestry, but if they are significant in the determination of economic outcomes of second-generation immigrants, who have been exposed to different economic conditions and institutions, only the cultural component should be relevant. Our empirical strategy exploits intergenerational transmission of culture. When people emigrate, they bring with them some aspects of their

\footnotetext{
${ }^{5}$ Since our data set contains information on both mother's and father's country of birth, we are able to distinguish individuals with two foreign-born parents from those with only one foreign-born parent. Therefore, this information allows us to examine the role of intermarriage in intergenerational cultural transmission. Fernández and Fogli (2009) use 1970 U.S. Census which only reports the father's country of birth when both parents are foreign-born. In their study, second-generation Americans are defined as individuals born in the U.S. with two foreign-born parents.

${ }^{6}$ As discussed in Fernández and Fogli (2009) this approach has its own problems. Immigrants may not represent their home country population. Their beliefs and preferences may be significantly different from the country average. Moreover, immigrants may be subject to several shocks resulting from immigration such as language difficulties, discrimination which could cause them to deviate from their traditional behavior. However, Fernández and Fogli (2009) point out that all the factors mentioned above create a bias towards finding culture to be insignificant.
} 
home culture and pass on their culture to the next generation. ${ }^{7}$ Bisin and Verdier (2001) introduce a theoretical model of intergenerational transmission of cultural traits in which the acquisition of culture-specific preferences by children is determined by the interaction between socialization inside the family and socialization outside the family, the cultural and social environments in which children live. Fernández et al. (2004) examine the transmission of cultural beliefs within the family. Using several data sets, they show that men whose mothers worked have a significantly higher probability of having a wife who works. Their findings provide evidence that family attitudes and their intergenerational transmission are important factors in the increase in women's involvement in the formal labor market over time. $^{8}$

Our empirical findings suggest that culture plays an important role in explaining the work behavior of women with immigrant parents from the same ethnic background. Women whose parents are from countries where women have high relative labor force participation rates work significantly more and women whose parents were born in countries where women have more children work significantly less. A one standard deviation increase in relative female LFPR corresponds to an increase of 0.75 hours worked per week. For comparison, the effect is about half of the impact of having university certificate on the number of hours worked per week. An increase in the total fertility rate (TFR) by one standard deviation, on the other hand, is associated with a decrease of 0.79 hours worked per week. Likewise, cultural proxies are statistically significant in explaining the labor force participation decision of women with immigrant parents. A one standard deviation increase in the relative female LFPR implies an increase of female labor force participation of 0.045 which is roughly $5.5 \%$ of the sample average of this variable. An increase in one standard deviation in TFR implies a reduction of female labor force participation of 0.031. The effect is about one fifth of the impact of

\footnotetext{
${ }^{7}$ Following Guiso et al. (2006) we define culture as a set of beliefs and values that ethnic, religious and social groups transmit fairly unchanged from generation to generation.

${ }^{8}$ Examining intergenerational transmission of fertility, human capital and work behavior of immigrants to their U.S.-born children, Blau et. al (2008) find that the immigrant generation's fertility and labor supply have a positive and significant effect on second-generation women's fertility and labor supply, respectively.
} 
being married on the probability of being in the labor force.

Consistent with the sociological literature that considers intermarriage as a sign of inclination toward cultural assimilation, we also find that the impact of cultural proxies is significantly larger for women with immigrant parents compared to those with intermarried parents.

We conduct a series of robustness checks to test the validity and strength of our estimates. We explore whether our results are driven by an omitted variable that is correlated with cultural proxies in a systematic fashion. For example, it is possible that countries with lower female labor force participation rate tend to have emigrants with lower human capital; these systematic differences in unobserved human capital across immigrant groups may be responsible for our results. We tackle this issue in two ways. First, we estimate the standard Mincerian wage equation to check whether the cultural proxies have any explanatory power for women's wages. The rationale for doing this exercise is as follows. If our cultural proxies were capturing some unobserved human capital, they would be statistically significant in predicting women's wages. We find that cultural proxies have no explanatory power in the wage equation. Therefore, it is unlikely that our results are driven by unobserved human capital. Second, we control for per capita GDP in the country of origin that is a proxy for cross-country differences in human capital. Our results do not change with the inclusion of this variable.

Female labor force participation rate in the country of ancestry depends on not only cultural norms but also economic and institutional environment such as child-support mechanism and female wages. Two countries with the same attitudes towards women working may have different female labor force participation rates because of their economic and institutional differences. In this case, cultural proxies capture only these differences rather than different cultural attitudes across countries. To alleviate this concern, we use a dummy variable for the woman's country of ancestry as an alternative approach. We show that our cultural proxies are significant in explaining the variation in the coefficients of the country 
dummies.

We also check whether the cultural proxies have quantitatively significant impacts on the work behavior of third-generation immigrant women. Our empirical findings provide evidence that the impact of culture does not persist into the third generation.

This study is organized as follows. The next section describes the data and variables used in the empirical analysis. Section 3 introduces our empirical model and presents results. Section 4 provides robustness tests of our findings while Section 5 concludes.

\section{Data and Descriptive Statistics}

The data used in our empirical analysis are from the 2001 Canadian Census Public Use Microdata File (PUMF) based on a 2.7\% sample of the population enumerated in the census. We focus on second-generation immigrant women aged 20-60. Second-generation immigrants are defined as those who were born in Canada and have at least one foreign-born parent. The PUMF provides information on the birthplace of the respondents' parents. This information allows us to distinguish children of immigrant parents from those of intermarried parents. The sample of second-generation immigrants with two immigrant parents consists of those with both parents who have the same ethnicity. We exclude individuals who are attending school either full-time or part-time from the analysis.

We use the 2000 values of the relative female LFPR and TFR from women's countries of ancestry as our cultural proxies. ${ }^{9}$ The relative female LFPR and TFR in the country of ancestry are the result of economic and institutional features of a society and cultural norms, such as views about male and female roles in society and the education of women. ${ }^{10}$

\footnotetext{
${ }^{9}$ As stated in Fernández (2007), it is not clear, a priori, whether we should use measures of culture that are contemporaneous or measures of culture that their parents brought when they immigrated to Canada. She discusses that if culture is evolving slowly over time, then the values that parents transmit are best reflected in what counterparts of these women are doing in the country of ancestry in 2000. It would be ideal to use both contemporaneous and past cultural values of their country of ancestry. Since we do not have information on parents' year of migration we use the values of cultural proxies from 2000. Using the same identification strategy, Alesina and Giuliano (2010) argue that the assumption that culture evolve slowly over time is credible and standard in the literature.

${ }^{10}$ Following Blau et al. (2011), we measure female LFPR in the country of ancestry relative to male LFPR
} 
However, only the latter remain relevant for second-generation immigrant women as they live in Canada where they experience a different economic and institutional environment. The data on the female LFPR and male LFPR in the country of ancestry are from the International Labour Organization (ILO). Female LFPR and male LFPR are the rate of economically active population for women and men respectively. ${ }^{11}$ The data on the total fertility rate (TFR) are from the United Nations Demographic Yearbook. The total fertility rate is defined as the average number of children a hypothetical cohort of women would have by the end of their reproductive period if they were subject during their whole lives to the fertility rates of a given historical period and if they were not subject to mortality. It is expressed as children per woman.

Figure 1 and 2 show the evolution of the relative female LFPR and TFR in each country of ancestry for the 1950-2000 period respectively. The relative female LFPR has increased in all countries over time. However, there has been a little change in their relative ranking, suggesting that cultural differences between countries stayed stable over time. Table 1 reports rank (Spearman) correlations across countries for the relative female LFPR between 1950 and 2000. They range from 0.56 to 0.98 . Table 2 shows rank correlations for TFR in the 1950-2000 period that vary from 0.52 to 0.97 . Figure 2 indicates that there has been a decline in TFR in all countries over time.

The census asks respondents to report the birthplace of their parents. However, the responses to these questions have been aggregated into five categories: Born in Canada, and born outside of Canada (United States, Europe, Asia, Other countries and regions) to preserve confidentiality. We use the ethnic origin question in the census to determine a

to alleviate problems in measuring the labor force. We find similar results when we use female LFPR in the country of ancestry rather than relative female LFPR. Male LFPR in 2000 does not show large variation. Male LFPR in 2000 is, on average, 56 with a standard deviation of 3.3. Moreover, the Spearman correlation across countries for female LFPR and relative female LFPR is 0.95 .

${ }^{11}$ The ILO provides a database that contains estimates and projections of the total population, the activity rates and the economically active population (labor force) by sex for the period 1950-2010 at tenyear intervals and for the year 1995. The economically active population consists of all persons who furnish the supply of labor for the production of goods and services (employed and unemployed, including first-time job seekers). The rates are calculated for individuals older than 15. 
woman's country of ancestry. ${ }^{12}$

Our final sample consists of 11,345 second-generation women and 18 countries of ancestry. In Table 3, we aggregate observations by country of ancestry. Column 1 shows female LFPR relative to male LFPR in 2000. Female LFPR/Male LFPR ranges between 0.876 and 0.401. China has the highest rate while Lebanon has the lowest one. Column 2 of Table 3 shows the TFR in 2000. It varies from 3.5 children in the Philippines to 1.1 children in Ukraine.

To examine the role of intermarriage in intergenerational cultural transmission, we divide the final sample into two subsamples: second-generation immigrant women with two immigrant parents from the same ethnic background (immigrant-family) and those with only one immigrant parent (mixed-family). Columns 5 and 7 in Table 3 show the average number of hours worked per week by country of ancestry for second-generation women with two immigrant parents and those with only one immigrant parent, respectively. In the immigrantfamily sample, women with Lebanese parents work 21.1 hours on average while women with Korean parents, on average, work 38.3 hours. In the mixed-family sample, women with an Indian parent have the lowest number of hours worked per week (11.6 hours), while women with a Korean parent have the highest (42.5 hours). ${ }^{13}$

The last two columns of Table 3 report the average number of hours worked per week by country of ancestry for third- and higher-generation women. ${ }^{14}$ Women with French and

\footnotetext{
${ }^{12}$ In the 2001 Census respondents were asked "To which ethnic or cultural group(s) did this person's ancestors belong?" The ethnic origin question gives 25 examples: Canadian, French, English, Chinese, Italian, German, Scottish, Irish, Cree, Micmac, Metis, Eskimo, East Indian, Ukrainian, Dutch, Polish, Portuguese, Filipino, Jewish, Greek, Jamaican, Vietnamese, Lebanese, Chilean and Somali. Respondents were required to write their ethnic origin(s) in four write-in spaces. Responses can be divided into two categories: selected single responses (persons who provided one ethnic origin only) and selected multiple response categories (persons who reported more than one ethnic origin). It is important to note that there is no double counting of the population in this variable. Persons who provided more than one ethnic origin are included in only one of the multiple-response categories. The sum of single and multiple responses is equal to the total population. See the 2001 Canadian Census PUMF Individuals File User Documentation for the multiple-response categories. We exclude those whose responses are categorized into the broader groupings such as African origins or Eastern European origins from which a country of ancestry can not be determined.

${ }^{13}$ Note that in the mixed-family sample, there are four countries with fewer than 10 observations. To check the robustness of our results, we exclude those countries from the analysis. Their exclusion does not affect the results.

${ }^{14}$ Third- and higher-generation women refer to those who were born in Canada and whose parents were born in Canada. For the sake of simplicity, we refer to third- and higher-generation group as the "third generation."
} 
British ancestry constitute $65 \%$ of the third generation women sample. Across countries, the average hours worked per week is 25.4 with a standard deviation of 3.6.

Columns 1-4 of Table 4 show the descriptive statistics for the sample of second-generation women by type of family. The women in the immigrant-family sample are, on average, 37 years old whereas the average age is 44 in the mixed-family sample. Most of the women in our sample live in Ontario, the largest province in Canada in terms of population. $82.4 \%$ of women with immigrant parents are in the labor force whereas this rate is $78.1 \%$ for women with intermarried parents. It appears that women with immigrant parents have a higher educational attainment than those with intermarried parents. For example, women with no degree make up $22.6 \%$ of the mixed-family sample and only $12.2 \%$ of the immigrant-family sample. $25.6 \%$ of women in the latter sample have at least university degree while women with at least university degree constitute $19.6 \%$ of the former sample. Table 4 indicates that over the $60 \%$ of women in both samples are married. Women with children at home constitute $64.3 \%$ and $66.6 \%$ of the immigrant-family and mixed-family samples respectively. ${ }^{15}$

Columns 5-6 of Table 4 report summary statistics for third-generation women. The educational attainment of third-generation women is lower than that of second-generation women. $77 \%$ of third-generation women are in the labor force. Like second-generation women, most of them are married and live in Ontario. Women with children at home make up $67.3 \%$ of the sample.

\footnotetext{
${ }^{15}$ Children is an indicator variable for the presence of children at home. The term "children" refers to blood, step- or adopted sons and daughters (regardless of age and marital status) who are living in the same dwelling as their parent(s), as well as to grandchildren in households where there are no parents present. Sons and daughters who are living with their spouse or common-law partner, or with one or more of their own sons and/or daughters, are not considered members of the census family of their parent(s), even if they are living in the same dwelling. In addition, those sons and daughters who do not live in the same dwelling as their parent(s) are not considered members of the census family of their parent(s) (Statistics Canada 2001). There is no direct fertility question in the 2001 Census.
} 


\section{Empirical Strategy and Results}

We test the following hypotheses.

Hypothesis 1: Culture matters to an important economic variable, female labor supply.

This hypothesis implies that our cultural proxies play an important role in explaining the variation in women's labor supply.

Hypothesis 2: The impact of the cultural proxies is significantly larger for women who have two immigrant parents with the same ethnic background than for those with one immigrant parent.

In line with the sociological literature suggesting that intermarriage reduces the ability of families to transmit a consistent ethnic culture to their children and thus acts as an agent of assimilation, we expect that the latter group is culturally more assimilated than the former group.

The empirical model is given by:

$$
\begin{aligned}
& H W_{i j}^{*}=\alpha_{0}+X_{i}^{\prime} \beta_{1}+C_{j}^{\prime} \beta_{2}+\varepsilon_{i j} \\
& H W_{i j}= \begin{cases}0 \quad \text { if } \quad H W_{i j}^{*} \leq 0 \\
H W_{i j}^{*} \quad \text { if } \quad H W_{i j}^{*}>0\end{cases}
\end{aligned}
$$

where $H W_{i j}$ is the number of hours worked in the previous week by a woman $i$ who is of ancestry $j . H W_{i j}$ takes a value of zero for women who do not work or a positive value for the number of hours worked. $X_{i}$ includes age, age squared, and indicator variables for educational level, marital status and place of residence. $C_{j}$ contains the proxies for culture, the female LFPR relative to male LFPR and TFR from women's countries of ancestry in 2000. Standard errors are corrected for clustering at the country of ancestry level, as the main variables of interest, cultural proxies, only vary with country of ancestry. To account for all the information in $H W_{i j}$ properly, we fit the model with the Tobit estimation method under the assumption that $\varepsilon_{i j}$ is normally distributed with mean zero and standard deviation 
$\sigma$.

Table 5 show OLS and Tobit estimation results for women with immigrant parents. The estimations are carried out through two specifications. The first specification uses only the relative female LFPR in the country of ancestry as a proxy for culture, while the second specification also includes TFR in the country of ancestry as a cultural proxy.

Column 1 of Table 5 indicates that the estimated coefficient of the relative female LFPR in the country of ancestry (Female LFPR/Male LFPR) has the expected positive sign and is statistically significant at the $5 \%$ level, implying that women whose parents come from countries where women have high relative LFPRs work significantly more than those whose parents come from countries with lower relative female LFPRs. Column 2 of Table 5 shows that when we include TFR as a cultural proxy as well, the coefficient of relative female LFPR decreases slightly in magnitude but remains statistically significant at the $5 \%$ level. The coefficient of TFR is negative and statistically significant at the $5 \%$ level indicating that women whose parents were born in countries where women have more children work significantly less themselves. Standardized OLS coefficients imply that a one standard deviation increase in the relative female LFPR leads to an increase of 0.51 hours worked per week which is $2 \%$ of the sample mean of this variable. A one standard deviation increase in TFR leads to a decrease of 0.62 hours worked per week. For comparison, an increase in one standard deviation in university certificate variable implies an increase of 1.28 hours worked per week which is roughly $4.6 \%$ of the sample mean.

Columns 4-6 of Table 5 report coefficients from the Tobit regression, and corresponding marginal effects of each explanatory variable on the probability that the observation is uncensored and on the expected number of hours worked per week given that the individual has not been censored for the first specification, respectively. Columns 6-8 of Table 5 report the estimation results for the second specification. Several conclusions can be drawn from Tobit estimates. First, and most importantly, the estimated coefficients of cultural proxies have the expected signs and are statistically significant at the $1 \%$ level. A one standard de- 
viation increase in the relative female LFPR in the country of ancestry leads to an increase of 0.75 hours worked per week, which is about $2.7 \%$ of the sample average. The effect is about half of the impact of having university certificate on the number of hours worked per week. An increase in TFR by one standard deviation, on the other hand, is associated with a decrease of 0.79 hours worked per week. For comparison, the effect is one fifth of the impact of being married. Second, other control variables have the expected sign and are statistically significant. The number of hours worked per week is an increasing and concave function of age. There is a significant positive relationship between education and the number of hours worked per week. Married and widowed women work less than their single counterparts.

Columns 4 and 7 of Table 5 indicate that the probability of working is significantly higher for women whose parents are from higher relative female LFPR countries. The coefficient of TFR is negative and statistically significant at the $1 \%$ level, suggesting that women whose parents are from higher TFR countries are less likely to work. The probability of working increases with education and is lower for married and widowed women compared to those who are single.

Table 6 reports OLS and Tobit estimation results for women with intermarried parents. Column 1 of Table 6 shows that the coefficient of relative female LFPR in the country of ancestry is positive but statistically insignificant at the conventional levels. When we use both relative female LFPR and TFR as cultural proxies, the coefficient of relative female LFPR remains statistically insignificant. TFR has a negative coefficient and it is statistically significant at the $10 \%$ level. A one standard deviation increase in TFR leads to a decrease of 0.49 hours worked per week. A comparison of column 2 of Table 5 with column 2 of Table 6 reveals that the impact of our cultural proxies is significantly larger for women with immigrant parents than for those with intermarried parents.

Consistent with our expectations, Tobit results in Table 6 show that cultural proxies do not have statistically significant explanatory power in the work behavior of second-generation immigrant women with intermarried parents. This finding provides evidence that women 
with intermarried parents are culturally more assimilated than those of immigrant parents. The remaining controls have the expected signs. The number of hours worked per week increases with age at a decreasing rate. Educational level has a positive impact on women's labor supply. Being married and widowed is associated with a decrease in hours worked per week.

The Census asks respondents to report their mother tongue, which refers to the first language learned at home in childhood and still understood by the individual at the time of survey. Language is an integral part of culture and it is the most important tool for transmitting culture from one generation to another. In line with our findings, the descriptive statistics indicate that $46 \%$ of women with immigrant parents report that their mother tongue is one of the non-official languages, while this rate for women with intermarried parents is only $9 \% .^{16}$

\section{Robustness Checks}

We test the robustness of our estimates by considering different specifications, estimation strategies, and potential source of omitted variable bias. We start by employing an alternative approach that uses indicator variables for women's country of ancestry as a proxy for culture. Fernández and Fogli (2009) point out that the advantage of this approach is that it allows us to capture different aspects of culture other than those captured by female LFPR and TFR in the country of ancestry. However, it suffers from not being explicit as to why it may make a difference to be of Lebanese rather than, say, German ancestry. Table 7 reports the coefficients of indicator variables for country of ancestry. The reference country is Lebanon, which has the lowest relative female LFPR in 2000. We use the sample of women with immigrant parents because the cultural proxies are statistically significant in this sample. ${ }^{17}$ In the regression, we control for age, age squared, educational level, marital

\footnotetext{
${ }^{16}$ The official languages in Canada are English and French.

${ }^{17} \mathrm{We}$ also estimated the same regression for women with intermarried parents. In line with our previous findings, we find that the coefficients of indicator variables for country of ancestry are statistically
} 
status and place of residence.

Table 7 shows that the coefficients of indicator variables for country of ancestry are statistically significant at the $1 \%$ level. The magnitude of the country of ancestry effect ranges from 1.95 to 12.4. As compared to women with Lebanese ancestry, women with Korean ancestry work, on average, 12.4 hours more per week while those with Israeli ancestry work, on average, only 1.95 hours more.

To examine whether the cultural proxies are significant in explaining the variation in the country fixed effect, we regress the estimated coefficients of indicator variables for country of ancestry on our cultural proxies. ${ }^{18}$ Table 8 reports the OLS results. The coefficient of the relative female LFPR is positive and statistically significant at the $10 \%$ level. A one standard deviation increase in the relative female LFPR corresponds to an increase of 1.21 in the country fixed effect, which is about $44 \%$ of the variation in the country-of-ancestry effect. ${ }^{19}$ Likewise, TFR plays an important role in explaining the variation in the country fixed effect. The estimated coefficient of TFR implies that a one standard deviation increase in TFR leads to a decrease of 1.25 in the country fixed effect which represents approximately $46 \%$ of the variation in the country-of-ancestry effect.

Second, we address the possibility of an omitted variable bias caused due to unobserved differences in human capital. As discussed in Fernández and Fogli (2009) parental education may differ in a systematic fashion by country of ancestry in a way that is correlated with the cultural proxies. For example, countries with higher female labor force participation may tend to have emigrants with higher human capital. Therefore, the differences in parental education levels may result in differences in unobserved human capital. ${ }^{20}$ Unfortunately, our data set does not contain information on the educational levels of parents. Fernández and insignificant.

${ }^{18}$ We estimate the following model: $\quad D_{j}=\delta_{1}+\delta_{2} C_{j}+\epsilon_{j}$

where $D_{j}$ is the coefficient on the country $j$ indicator variable reported in Table $7, C_{j}$ is the cultural proxy and $\epsilon_{j}$ is an error term.

${ }^{19}$ The average country-of-ancestry effect is 6.70 with a standard deviation of 2.74 .

${ }^{20}$ If intergenerational transmission of education takes place then controlling for the woman's education level may alleviate the problem of unobserved human capital. 
Fogli (2009) argue that if the cultural proxy were correlated with the systematic differences in unobserved human capital, then it should have explanatory power in the wage equation. They estimate the standard Mincer regression and show that their cultural proxy does not help predict women's wages. In order to test that our results are not driven by unobserved human capital, we did the same exercise. Table 9 shows the results from the standard Mincerian wage equation accounting for potential selection into the workforce. We assume that marital status affects whether a woman participates in the labor force but does not have a direct effect on the wage. ${ }^{21}$ We regress log hourly wages on education indicator variables, potential experience, potential experience squared, indicator variables for place of residence and cultural proxies. The hourly wage variable is constructed by the division of gross annual wage and salary income in 2000 by the annual hours of work (the number of weeks worked in 2000 multiplied by the number of hours worked in the reference week). ${ }^{22}$ According to the minimum wage database of Human Resources and Skills Development of Canada, the minimum wage in British Columbia for adult workers is eight Canadian dollars which is the highest rate in 2000 across provinces. Therefore, individuals with an hourly wage of less than eight Canadian dollars are excluded from analysis. ${ }^{23}$ Like Fernández and Fogli (2009), we find that our cultural proxies are not statistically significant in predicting women's wages, providing evidence that our results are not driven by unobserved human capital.

To tackle the issue of unobserved parental human capital, we also check the robustness of our results to the inclusion of GDP per capita in 2000 in the country of origin which captures the cross-country differences in human capital. ${ }^{24}$ The results are shown in Table 11. The coefficient of GDP per capita variable is negative and statistically insignificant in

\footnotetext{
${ }^{21}$ The results of the selection equations are not reported. We find that marital status has an explanatory power in the selection equation. As expected, being married is associated with a decrease in the probability of being in the labor force.

${ }^{22}$ We assume that the number of hours worked in the week preceding Census day (May 15, 2001) represents the average weekly hours worked.

${ }^{23}$ See the detailed information on hourly minimum wages in Canada for adult workers since 1965 at this link: http ://srv116.services.gc.ca/dimt - wid/sm $-m w / r p t 2 . a s p x ? l a n g=$ engdec $=1$. The inclusion of those observations does not change the results.

${ }^{24}$ The data on per capita GDP are from United Nations Statistics. It is important to note that using per capita GDP from previous decades yields similar results.
} 
both immigrant-family and mixed-family samples. The inclusion of this variable decreases the magnitudes of cultural proxies slightly but they remain statistically significant in the immigrant-family sample and insignificant in the mixed-family sample.

We examine the impact of culture on the labor force participation decision. Table 10 reports marginal effects from probit estimates of probability of being in the labor force. Consistent with our previous results, cultural proxies have expected signs and statistically significant in the sample of women with immigrant parents while they are not statistically significant at conventional levels in the sample of women with intermarried parents. The second column of Table 10 indicates that a one standard deviation increase in the relative female LFPR leads to an increase of female labor force participation of 0.045 which is roughly $5.5 \%$ of the sample average of this variable. The effect is half of the magnitude of the impact of one standard deviation in the education variable corresponding to university certificate. An increase in one standard deviation in the total fertility rate (TFR) implies a reduction in the probability of being in the labor force of 0.031 which is equivalent to $3.8 \%$ of the sample average.

We check the robustness of our results to the inclusion of an indicator variable for the presence of children at home (Children). The results are reported in Table 11. Women with children at home work significantly less than those without children at home. In the immigrant-family sample, coefficients of cultural proxies remain statistically significant. The inclusion of Children variable leads to a decrease in the magnitude of TFR in the absolute value suggesting that women whose parents are from higher TFR countries are more likely to have children at home. On the other hand, the magnitude of coefficient of relative female LFPR increases implying that the correlation between having parents from high relative female LFPR countries and the presence of children at home is negative. In line with our previous results, the coefficients of cultural proxies are not statistically significant in the mixed-family sample.

Table 3 shows that in the mixed family sample there are four countries with fewer than 
10 observations: India, Jamaica, the Philippines and South Korea. We examine whether our results are robust to the exclusion of those countries from the analysis. Table 12 indicates that excluding these countries does not change the results. Likewise, the results are robust to the exclusion of the largest immigrant group, those from the U.K., in the mixed-family sample.

We explore whether cultural proxies have significant explanatory power for the work behavior of third-generation women. Since we find effect of cultural proxies to be significantly weaker for second-generation women with intermarried parents, we expect this effect to be even weaker or non-existent for third-generation women. The results reported in Table 13 support our hypothesis and show that the coefficients of cultural proxies are statistically insignificant at conventional levels, suggesting the dilution of cultural transmission across generations.

\section{Conclusion}

Using 2001 Canadian Census data, we examine the effect of culture on the work behavior of second-generation immigrant women. We add to the current literature by analyzing the role of intermarriage in intergenerational transmission of culture and its subsequent effect on labor market outcomes. In the sociological literature, marrying outside one's own ethnic group is accepted as the most tangible and visible form of behavioral and cultural assimilation. In line with this literature, we test whether the impact of the cultural proxies is larger for women with immigrant parents from the same ethnic background than for those with intermarried parents.

We use relative female LFPR and TFR in the country of ancestry as our cultural proxies. The rationale for using these variables as our cultural proxies is that when individuals emigrate, they bring with them some aspects of their home culture and transmit their culture to the next generation. Female LFPR and TFR in the country of ancestry reflect 
economic conditions, institutions, and cultural norms in society. If the cultural proxies have a significant effect on the work outcome of second-generation Canadian women, then only the cultural component of these variables should be responsible for this significant relationship, as second-generation immigrant women live in Canada with a different economic and institutional environment.

Our findings provide evidence that culture matters in determining the female labor supply. The cultural proxies are significant in explaining how much second-generation Canadian women with immigrant parents work. A one standard deviation increase in the relative female LFPR in the country of ancestry leads to an increase of 0.75 hours worked per week. The effect is about the half of the effect of having university certificate. An increase in TFR by one standard deviation, on the other hand, corresponds to a decrease of 0.79 hours worked per week, which is $21 \%$ of the variation in hours worked per week across ancestries. Consistent with our expectations, we also find that the impact of cultural proxies is significantly larger for women with immigrant parents than for those with intermarried parents. Our results are robust to different specifications and estimation strategies.

It would be interesting to explore different aspects of the relationship between intermarriage and culture. How does the marriage decision of a second-generation woman with immigrant parents affect her work outcome? Is the impact of culture is stronger for secondgeneration women married within their own ethnic group than for intermarried women. Whose culture, parents' or husband's, dominates? Limitations of the data do not allow us to answer these questions in the current study. 


\section{References}

Alesina, Alberto and Paola Giuliano (2010). "The Power of the Family." Journal of Economic Growth, 15(2), 93-125.

Antecol, Heather (2000). "An Examination of Cross-Country Differences in the Gender Gap in Labor Force Participation Rates." Labour Economics, 7(4), 409-426.

Antecol, Heather (2001). "Why is There Interethnic Variation in the Gender Wage Gap?: The Role of Cultural Factors." The Journal of Human Resources, 36(1), 119-143.

Blau, Francine D., Lawrence M. Kahn , Albert Y. Liu, and Kerry L. Papps (2008). "The Transmission of Women's Fertility, Human Capital and Work Orientation across Immigrant Generation." Working Paper No. 14388, National Bureau of Economic Research.

Blau, Francine D., Lawrence M. Kahn and Kerry Papps (2011). "Gender, Source Country Characteristics and Labor Market Assimilation Among Immigrants:1980-2000. "Review of Economics and Statistics, 93(1), 43-58.

Bisin, Alberto, and Thierry Verdier (2000). "Beyond the Melting Pot: Cultural Transmission, Marriage, and the Evolution of Ethnic and Religious Traits." The Quarterly Journal of Economics, 3:955-988.

Bisin, Alberto and Thierry Verdier (2001). "The Economics of Cultural Transmission and the Dynamics of Preferences." Journal of Economic Theory, 97(2), 298-319.

Carroll, Christopher D., Byung-Kun B. Rhee, and Changyong Rhee (1994). "Are There Cultural Effects on Saving? Some Cross-Sectional Evidence." Quarterly Journal of Economics, 109(3), 685-699.

Fernández, Raquel, Alessandra Fogli, and Claudia Olivetti (2004). "Mothers and Sons: Preference Formation and Female Labor Force Dynamics." Quarterly Journal of Economics, 119(4), 1249-1299.

Fernández, Raquel, and Alessandra Fogli (2006). "Fertility: The Role of Culture and Family Experience." Journal of the European Economic Association, 4(2-3), 552-561. 
Fernández, Raquel (2007). "Women, Work, and Culture." Journal of the European Economic Association, 5(2-3), 305-332.

Fernández, Raquel (2008). "Culture and Economics." In New Palgave Dictionary of Economics, edited by Steven N. Durlauf and Lawrence E. Blume. Palgrave Macmillan.

Fernández, Raquel, and Alessandra Fogli (2009)."Culture: An Empirical Investigation of Beliefs, Work, and Fertility." American Economic Journal: Macroeconomics, American Economic Association, 1(1), 146-177.

Fernández, Raquel (2010). "Does Culture Matter?" Working Paper No. 5122, IZA.

Giuliano, Paola (2007). "Living Arrangements in Western Europe: Does Cultural Origin Matter?" Journal of the European Economic Association, 5(5), 927-952.

Gordon, Milton M. (1964). Assimilation in American Life. Oxford University Press.

Guiso Luigi, Sapienza Paola, and Luigi Zingales (2006). "Does Culture Affect Economic Outcomes." Journal of Economic Perspective, 20(2), 23-48.

International Labor Office (1996). "Economically Active Population, 1950-2010." Fourth Edition, Geneva.

Pagnini, Deanna L. and S. P. Morgan (1990). "Intermarriage and the Social Distance Among U.S. Immigrants at the Turn of the Century," American Journal of Sociology, 96(2), 405432.

Qian, Zhenchao (1999)."Who Intermarries? Education, Nativity Region, and Interracial Marriage 1980 and 1990." Journal of Comparative Family Studies, 30(4), 579-597.

Qian, Zhenchao and Daniel T. Lichter (2001)."Measuring Marital Assimilation: Intermarriage among Natives and Immigrants." Social Science Research, 30(2), 289-312. 
Figure 1

Relative Female Labor Force Participation 1950-2000

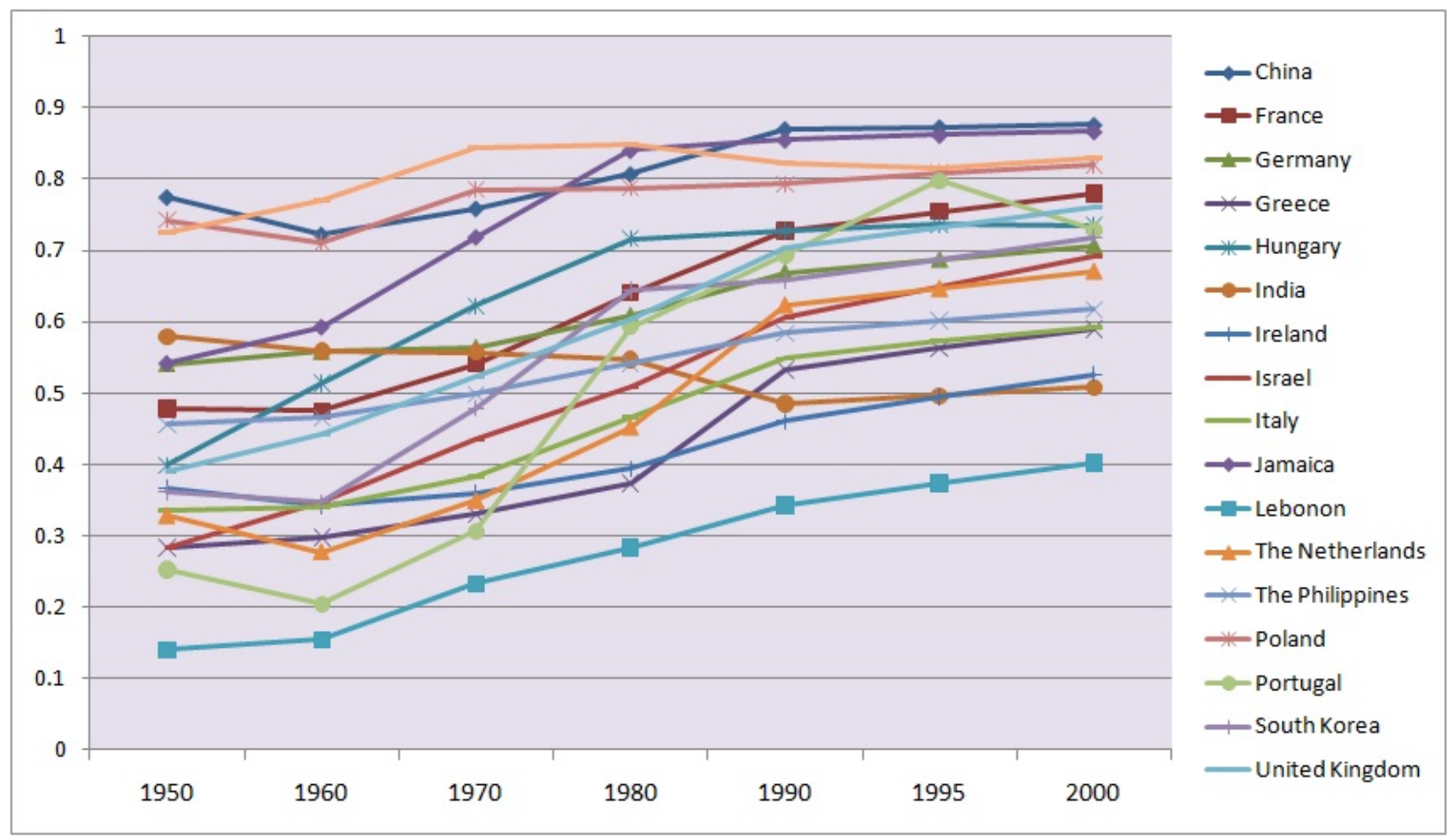


Figure 2

Total Fertility Rate 1950-2000

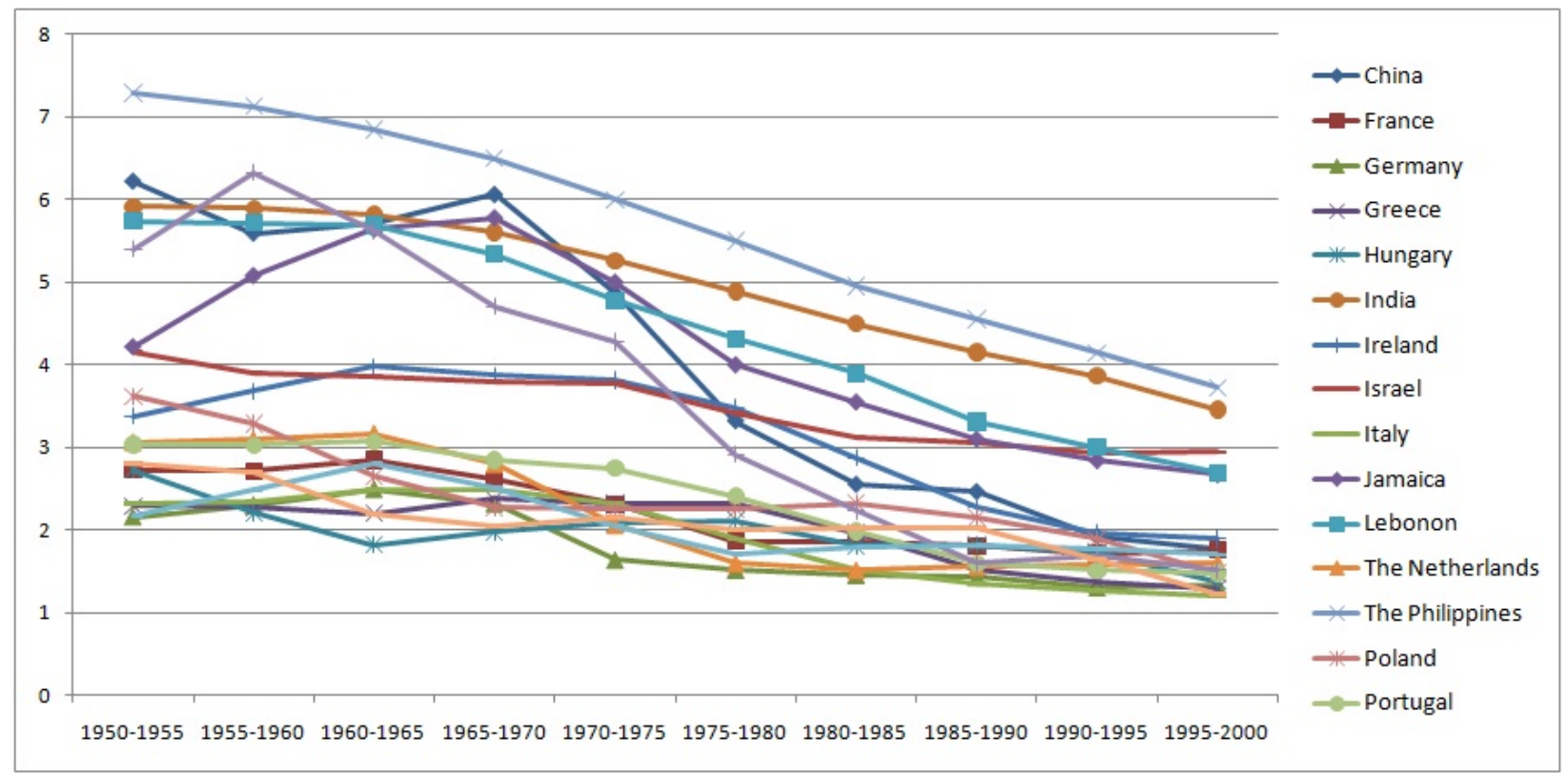


Table 1

Rank Correlations across countries for the relative female LFPR in the 1950-2000 period

\begin{tabular}{cccccccc}
\hline \hline & $\mathbf{1 9 5 0}$ & $\mathbf{1 9 6 0}$ & $\mathbf{1 9 7 0}$ & $\mathbf{1 9 8 0}$ & $\mathbf{1 9 9 0}$ & $\mathbf{1 9 9 5}$ & $\mathbf{2 0 0 0}$ \\
\hline $\mathbf{1 9 5 0}$ & 1.0000 & & & & & & \\
$\mathbf{1 9 6 0}$ & 0.9505 & 1.0000 & & & & & \\
$\mathbf{1 9 7 0}$ & 0.9298 & 0.9814 & 1.0000 & & & & \\
$\mathbf{1 9 8 0}$ & 0.7606 & 0.8308 & 0.8824 & 1.0000 & & & \\
$\mathbf{1 9 9 0}$ & 0.6244 & 0.6904 & 0.7606 & 0.9154 & 1.0000 & & \\
$\mathbf{1 9 9 5}$ & 0.5604 & 0.6326 & 0.6904 & 0.9009 & 0.9814 & 1.0000 & \\
$\mathbf{2 0 0 0}$ & 0.5955 & 0.6636 & 0.7276 & 0.9009 & 0.9876 & 0.9835 & 1.0000 \\
\hline \hline
\end{tabular}




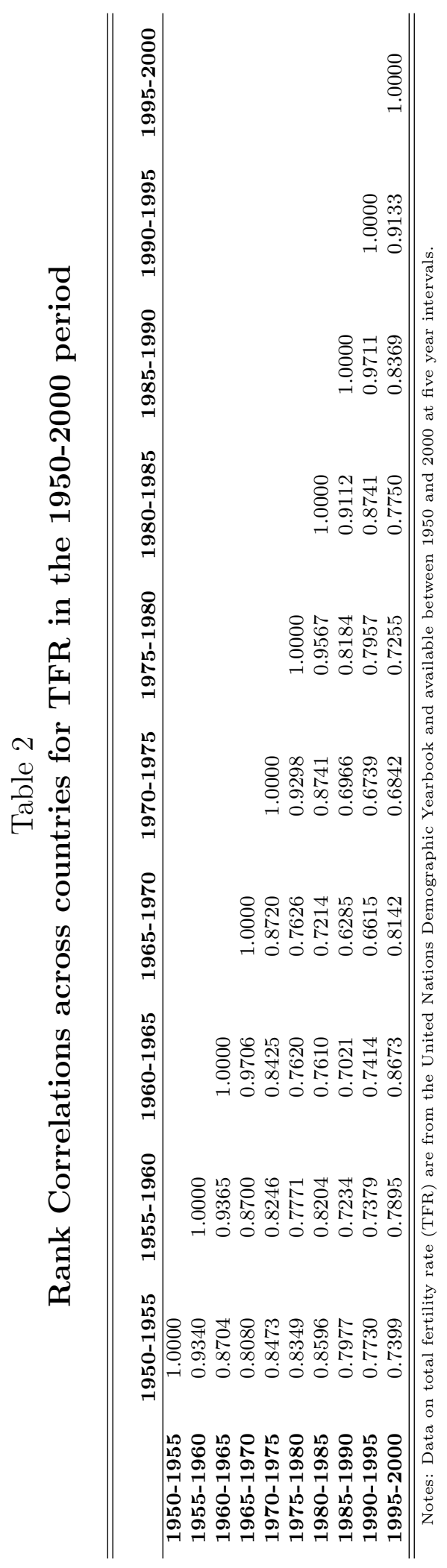




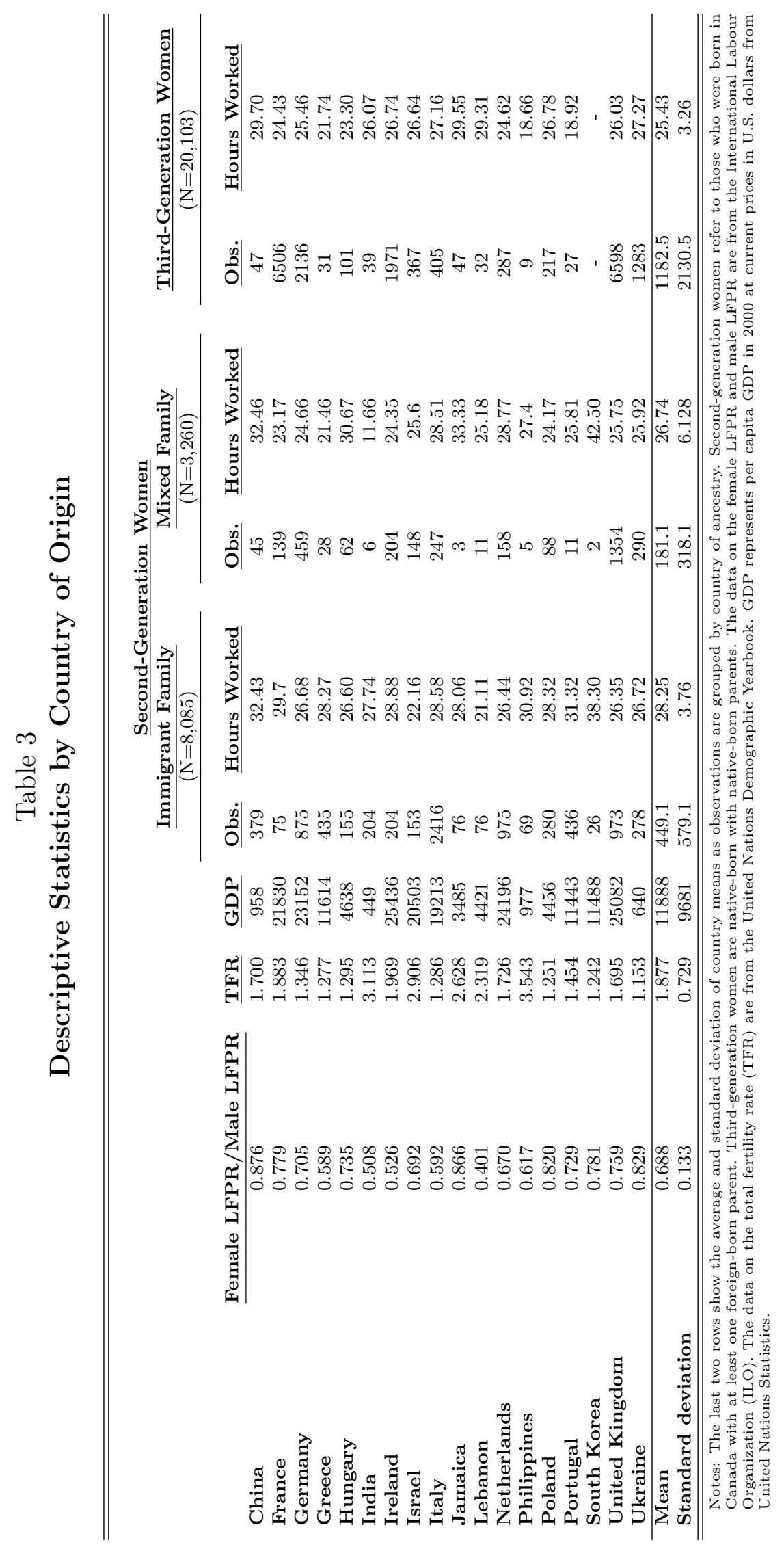




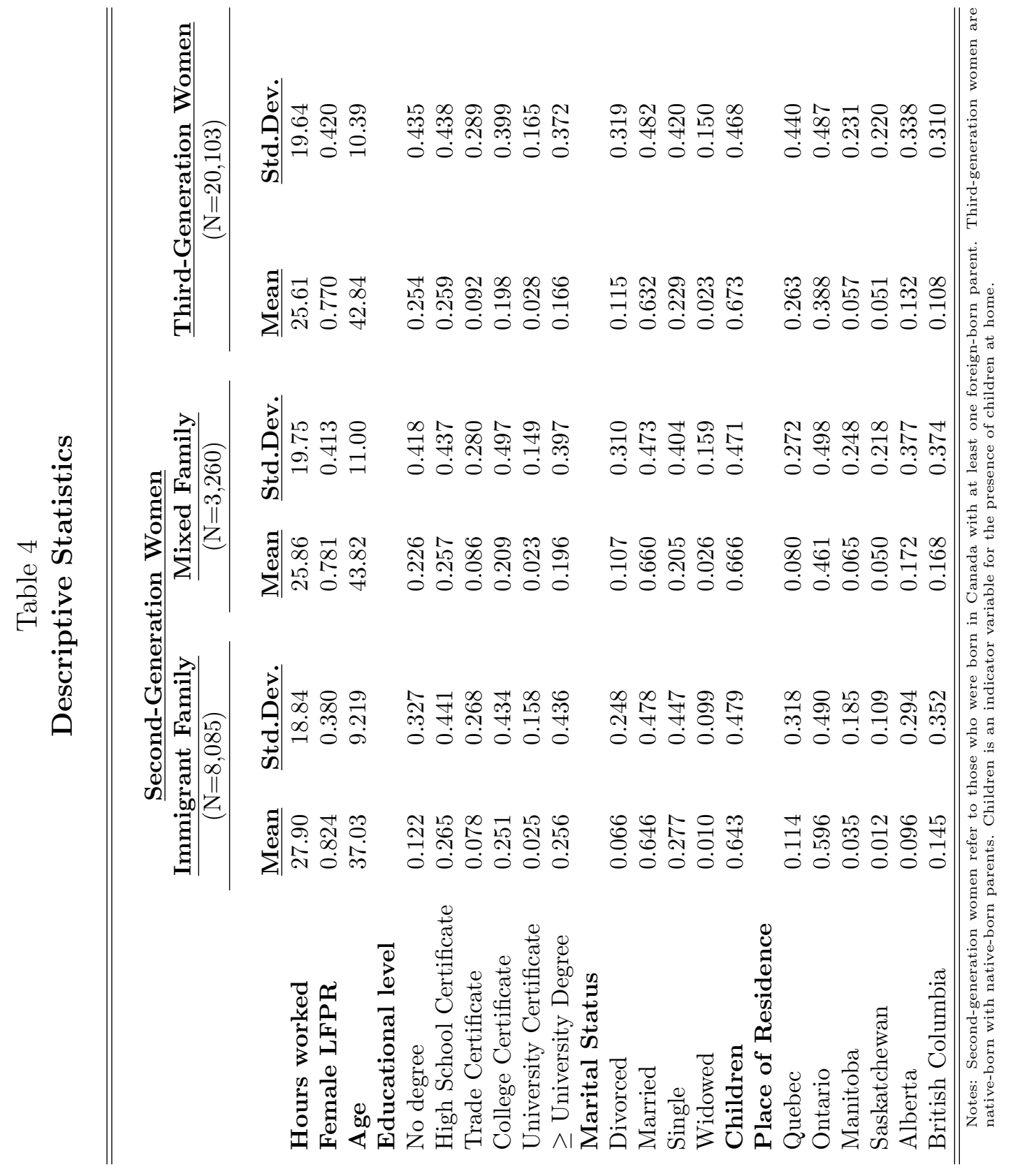




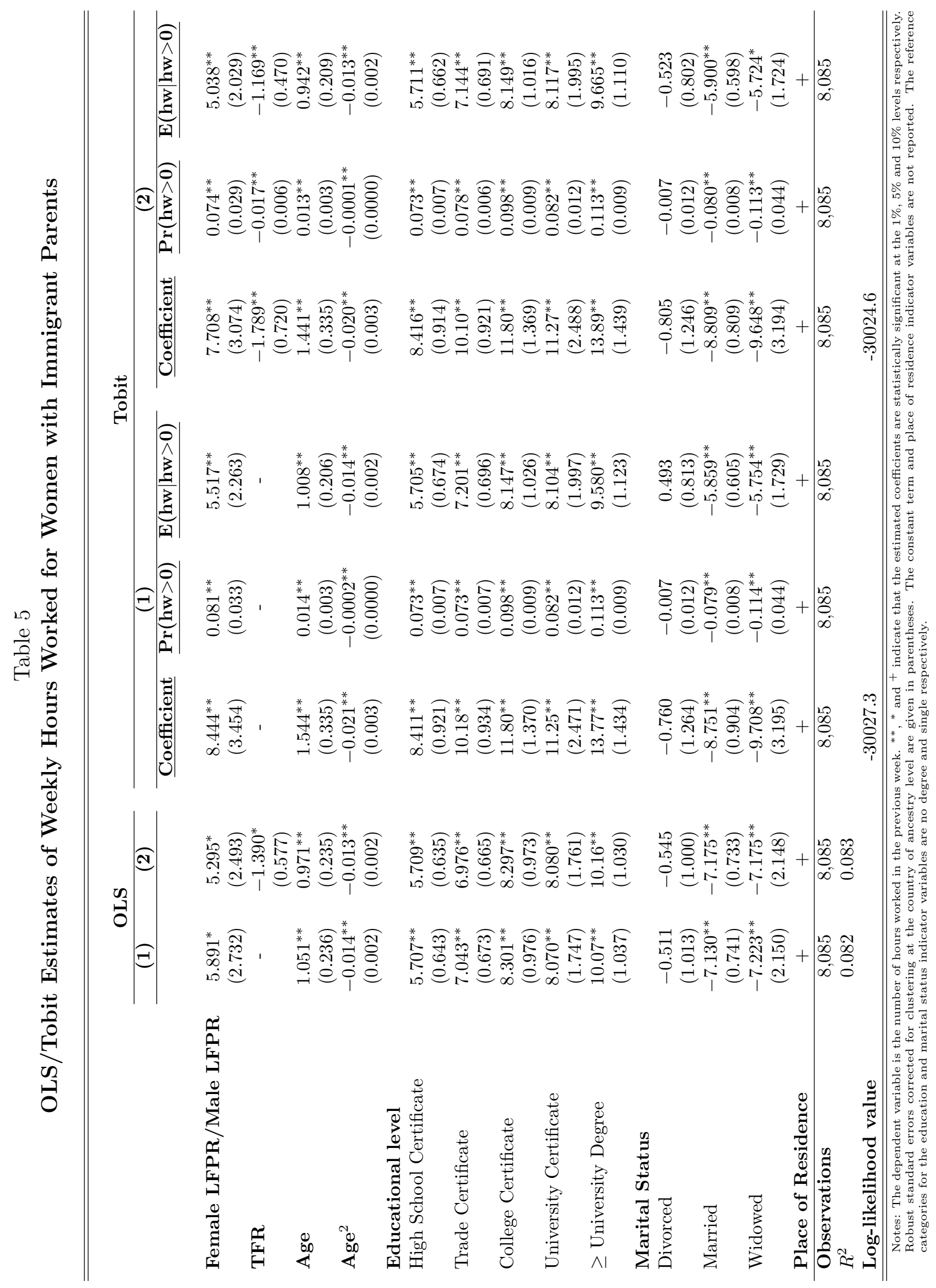




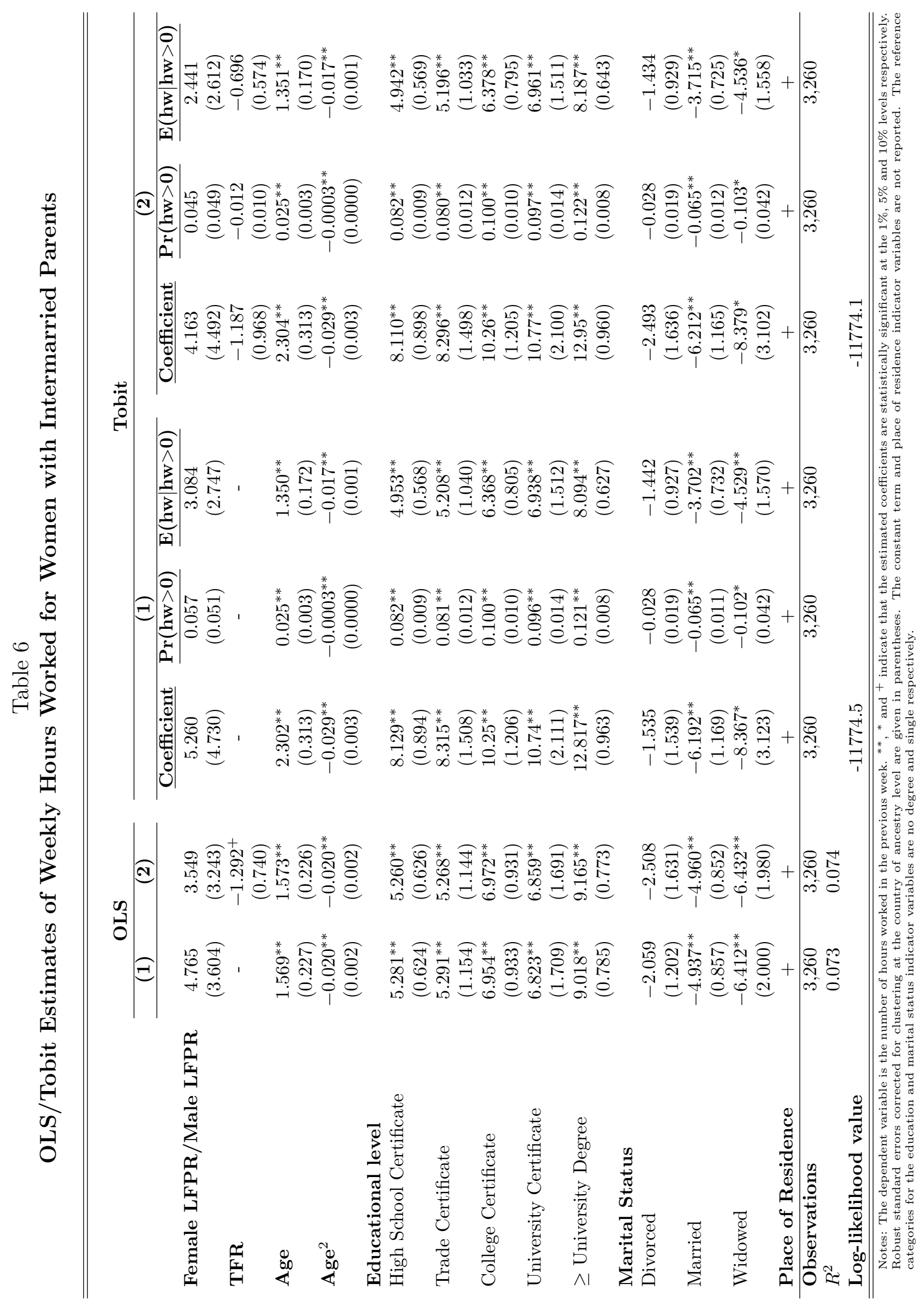


Table 7

Country-of-Ancestry Indicator Variables

\begin{tabular}{|c|c|c|}
\hline \multirow[b]{3}{*}{ United Kingdom } & \multicolumn{2}{|c|}{ Hours worked } \\
\hline & Coefficient & Std. Error \\
\hline & $6.660^{* *}$ & 0.694 \\
\hline Ireland & $8.267^{* *}$ & 0.557 \\
\hline France & $7.797^{* *}$ & 0.474 \\
\hline Germany & $6.874^{* *}$ & 0.668 \\
\hline Netherlands & $6.139^{* *}$ & 0.674 \\
\hline Ukraine & $7.591^{* *}$ & 0.669 \\
\hline Poland & $7.449^{* *}$ & 0.611 \\
\hline Hungary & $5.783^{* *}$ & 0.640 \\
\hline Portugal & $10.30^{* *}$ & 0.263 \\
\hline Italy & $6.987^{* *}$ & 0.401 \\
\hline Greece & $6.015^{* *}$ & 0.307 \\
\hline Israel & $1.955^{* *}$ & 0.504 \\
\hline Jamaica & $5.469^{* *}$ & 0.395 \\
\hline India & $5.171^{* *}$ & 0.287 \\
\hline China & $8.622^{* *}$ & 0.448 \\
\hline Philippines & $7.174^{* *}$ & 0.331 \\
\hline South Korea & $12.42^{* *}$ & 0.423 \\
\hline Observations & 8,085 & \\
\hline$R^{2}$ & 0.077 & \\
\hline
\end{tabular}


Table 8

The Relationship between Country-of-Ancestry Effects and Cultural Proxies

\begin{tabular}{|c|c|}
\hline & Country-of-Ancestry Effect \\
\hline Female LFPR/Male LFPR & $\begin{array}{l}9.320^{+} \\
(5.123)\end{array}$ \\
\hline TFR & $\begin{array}{c}-1.719^{+} \\
(0.913)\end{array}$ \\
\hline Observations & 18 \\
\hline$R^{2}$ & 0.209 \\
\hline
\end{tabular}

Table 9

Wage Equation Parameter Estimates

\begin{tabular}{|c|c|c|c|c|}
\hline & \multicolumn{4}{|c|}{ Log(hourly wage) } \\
\hline & \multicolumn{2}{|c|}{ Immigrant Family } & \multicolumn{2}{|c|}{ Mixed Family } \\
\hline & $(1)$ & $(2)$ & (1) & $(2)$ \\
\hline \multirow[t]{2}{*}{ Female LFPR/Male LFPR } & 0.086 & 0.095 & 0.185 & 0.188 \\
\hline & $(0.088)$ & $(0.093)$ & $(0.164)$ & $(0.157)$ \\
\hline \multirow[t]{2}{*}{ TFR } & - & 0.024 & - & 0.006 \\
\hline & & $(0.023)$ & & $(0.044)$ \\
\hline \multicolumn{5}{|l|}{ Educational level } \\
\hline \multirow[t]{2}{*}{ High School Certificate } & $0.232^{* *}$ & $0.232^{* *}$ & $0.274^{* *}$ & $0.274^{* *}$ \\
\hline & $(0.028)$ & $(0.028)$ & $(0.053)$ & $(0.053)$ \\
\hline \multirow[t]{2}{*}{ Trade Certificate } & $0.173^{* *}$ & $0.173^{* *}$ & $0.281^{* *}$ & $0.281^{* *}$ \\
\hline & $(0.038)$ & $(0.039)$ & $(0.073)$ & $(0.073)$ \\
\hline \multirow[t]{2}{*}{ College Certificate } & $0.361^{* *}$ & $0.361^{* *}$ & $0.352^{* *}$ & $0.352^{* *}$ \\
\hline & $(0.030)$ & $(0.030)$ & $(0.074)$ & $(0.074)$ \\
\hline \multirow[t]{2}{*}{ University Certificate } & $0.430^{* *}$ & $0.430^{* *}$ & $0.395^{* *}$ & $0.395^{* *}$ \\
\hline & $(0.058)$ & $(0.058)$ & $(0.055)$ & $(0.056)$ \\
\hline \multirow[t]{2}{*}{$\geq$ University Degree } & $0.663^{* *}$ & $0.062^{* *}$ & $0.649^{* *}$ & $0.648^{* *}$ \\
\hline & $(0.031)$ & $(0.030)$ & $(0.074)$ & $(0.074)$ \\
\hline \multirow[t]{2}{*}{ Experience } & $0.036^{* *}$ & $0.037^{* *}$ & $0.041^{* *}$ & $0.041^{* *}$ \\
\hline & $(0.002)$ & $(0.002)$ & $(0.004)$ & $(0.004)$ \\
\hline \multirow[t]{2}{*}{ Experience $^{2} / \mathbf{1 0 0}$} & $-0.079^{* *}$ & $-0.080^{* *}$ & $-0.094^{* *}$ & $-0.094^{* *}$ \\
\hline & $(0.007)$ & $(0.007)$ & $(0.009)$ & $(0.009)$ \\
\hline Observations & 7,359 & 7,359 & 2,939 & 2,939 \\
\hline Uncensored observations & 4,900 & 4,900 & 1,784 & 1,784 \\
\hline Log pseudolikelihood & -7730 & -7729 & -3155 & -3155 \\
\hline LR test for $\rho=\mathbf{0}$ & 573.6 & 566.8 & 318.5 & 313.5 \\
\hline$\left(\right.$ Prob $\left.>\chi^{2}(1)\right)$ & $(0.000)$ & $(0.000)$ & $(0.000)$ & $(0.000)$ \\
\hline
\end{tabular}


Table 10

\section{Probit Estimates of Labor Force Participation}

\begin{tabular}{|c|c|c|c|c|}
\hline & \multicolumn{4}{|c|}{$\mathbf{P}($ being in the labor force $)$} \\
\hline & \multicolumn{2}{|c|}{ Immigrant Family } & \multicolumn{2}{|c|}{ Mixed Family } \\
\hline & (1) & $(2)$ & (1) & $(2)$ \\
\hline \multirow[t]{2}{*}{ Female LFPR/Male LFPR } & $0.121^{* *}$ & $0.112^{* *}$ & 0.030 & 0.016 \\
\hline & $(0.044)$ & $(0.040)$ & $(0.102)$ & $(0.098)$ \\
\hline \multirow[t]{2}{*}{ TFR } & - & $-0.017^{*}$ & - & -0.014 \\
\hline & & $(0.008)$ & & $(0.021)$ \\
\hline \multirow[t]{2}{*}{ Age } & $0.016^{* *}$ & $0.015^{* *}$ & $0.028^{* *}$ & $0.028^{* *}$ \\
\hline & $(0.005)$ & $(0.005)$ & $(0.004)$ & $(0.004)$ \\
\hline \multirow[t]{2}{*}{ Age $^{2}$} & $-0.0002^{* *}$ & $-0.0002^{* *}$ & $-0.0003^{* *}$ & $-0.0003^{* *}$ \\
\hline & $(0.0000)$ & $(0.0000)$ & $(0.0000)$ & $(0.0000)$ \\
\hline \multicolumn{5}{|l|}{ Educational level } \\
\hline \multirow[t]{2}{*}{ High School Certificate } & $0.094^{* *}$ & $0.094^{* *}$ & $0.084^{* *}$ & $0.084^{* *}$ \\
\hline & $(0.009)$ & $(0.009)$ & $(0.017)$ & $(0.017)$ \\
\hline \multirow[t]{2}{*}{ Trade Certificate } & $0.105^{* *}$ & $0.105^{* *}$ & $0.099^{* *}$ & $0.099^{* *}$ \\
\hline & $(0.007)$ & $(0.007)$ & $(0.018)$ & $(0.018)$ \\
\hline \multirow[t]{2}{*}{ College Certificate } & $0.141^{* *}$ & $0.141^{* *}$ & $0.122^{* *}$ & $0.122^{* *}$ \\
\hline & $(0.009)$ & $(0.009)$ & $(0.010)$ & $(0.010)$ \\
\hline \multirow[t]{2}{*}{ University Certificate } & $0.106^{* *}$ & $0.106^{* *}$ & $0.125^{* *}$ & $0.125^{* *}$ \\
\hline & $(0.019)$ & $(0.020)$ & $(0.020)$ & $(0.020)$ \\
\hline \multirow[t]{2}{*}{$\geq$ University Degree } & $0.155^{* *}$ & $0.156^{* *}$ & $0.145^{* *}$ & $0.147^{* *}$ \\
\hline & $(0.011)$ & $(0.011)$ & $(0.014)$ & $(0.013)$ \\
\hline \multicolumn{5}{|l|}{ Marital Status } \\
\hline \multirow[t]{2}{*}{ Divorced } & 0.002 & 0.002 & 0.006 & 0.006 \\
\hline & $(0.014)$ & $(0.014)$ & $(0.024)$ & $(0.041)$ \\
\hline \multirow[t]{2}{*}{ Married } & $-0.083^{* *}$ & $-0.083^{* *}$ & $-0.063^{* *}$ & $-0.063^{* *}$ \\
\hline & $(0.011)$ & $(0.010)$ & $(0.017)$ & $(0.017)$ \\
\hline \multirow[t]{2}{*}{ Widowed } & $-0.115^{*}$ & $-0.114^{*}$ & -0.065 & -0.065 \\
\hline & $(0.051)$ & $(0.051)$ & $(0.066)$ & $(0.066)$ \\
\hline Place of Residence & + & + & + & + \\
\hline Observations & 8,085 & 8,085 & 3,260 & 3,260 \\
\hline
\end{tabular}




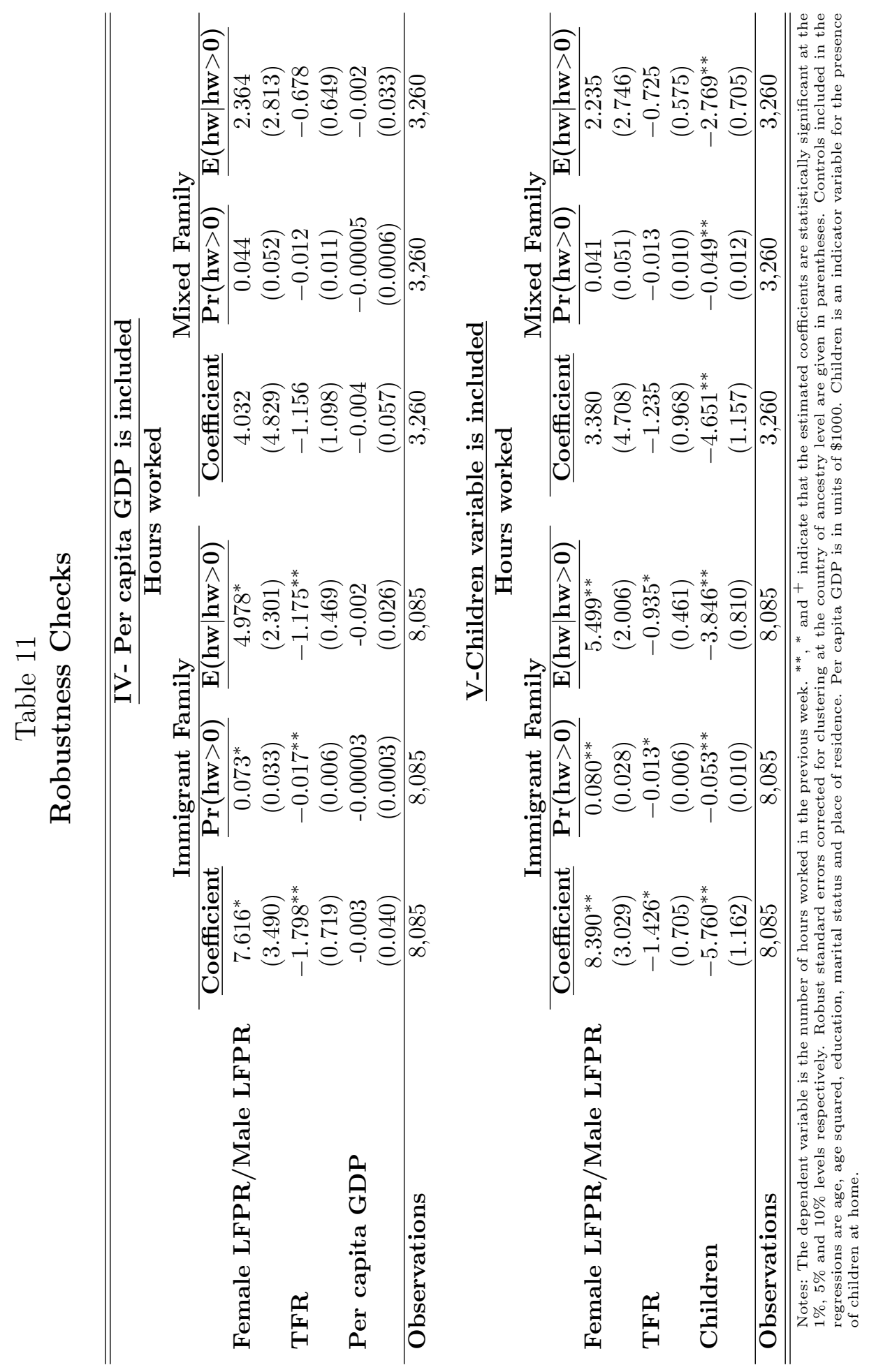




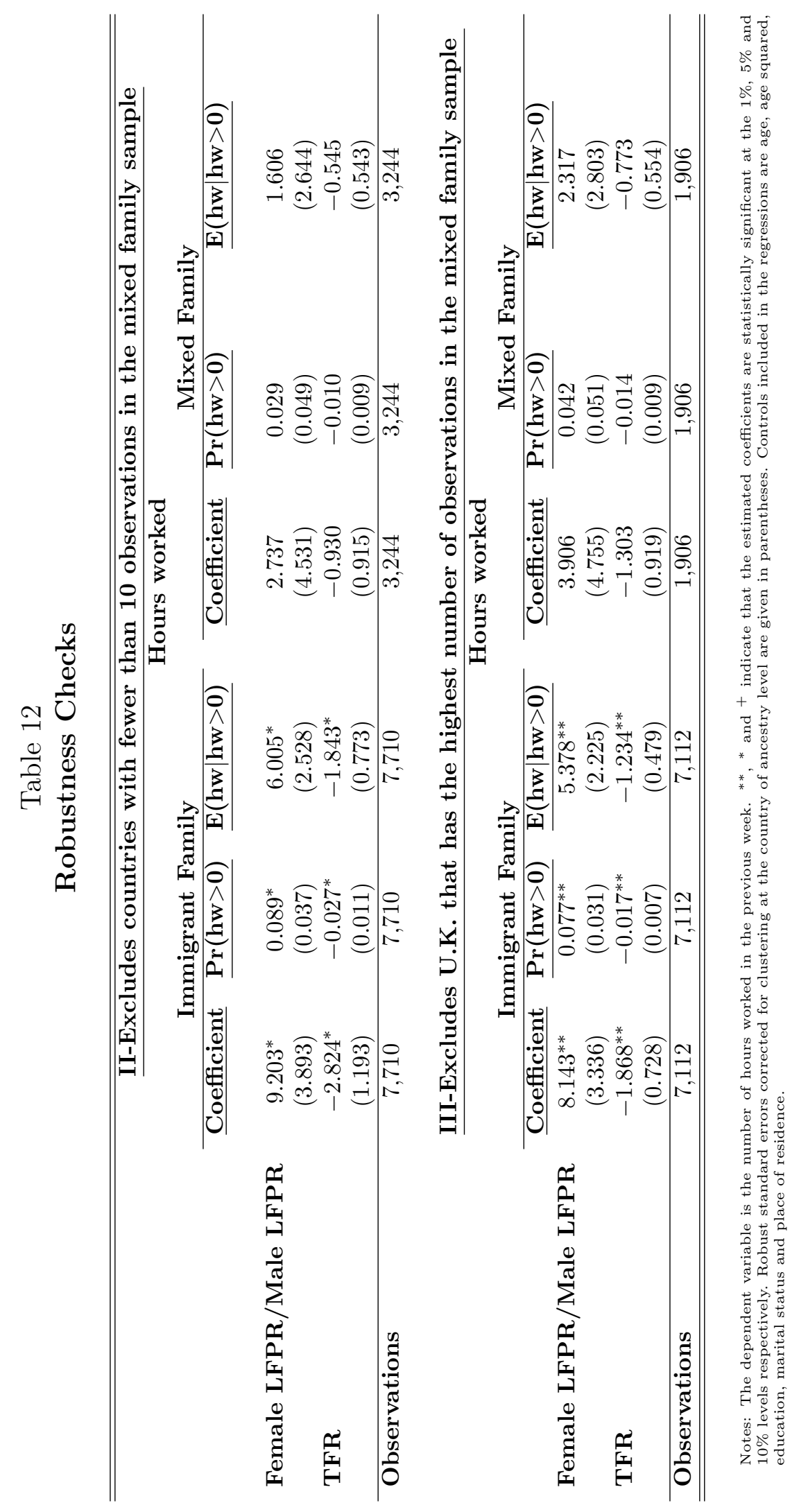




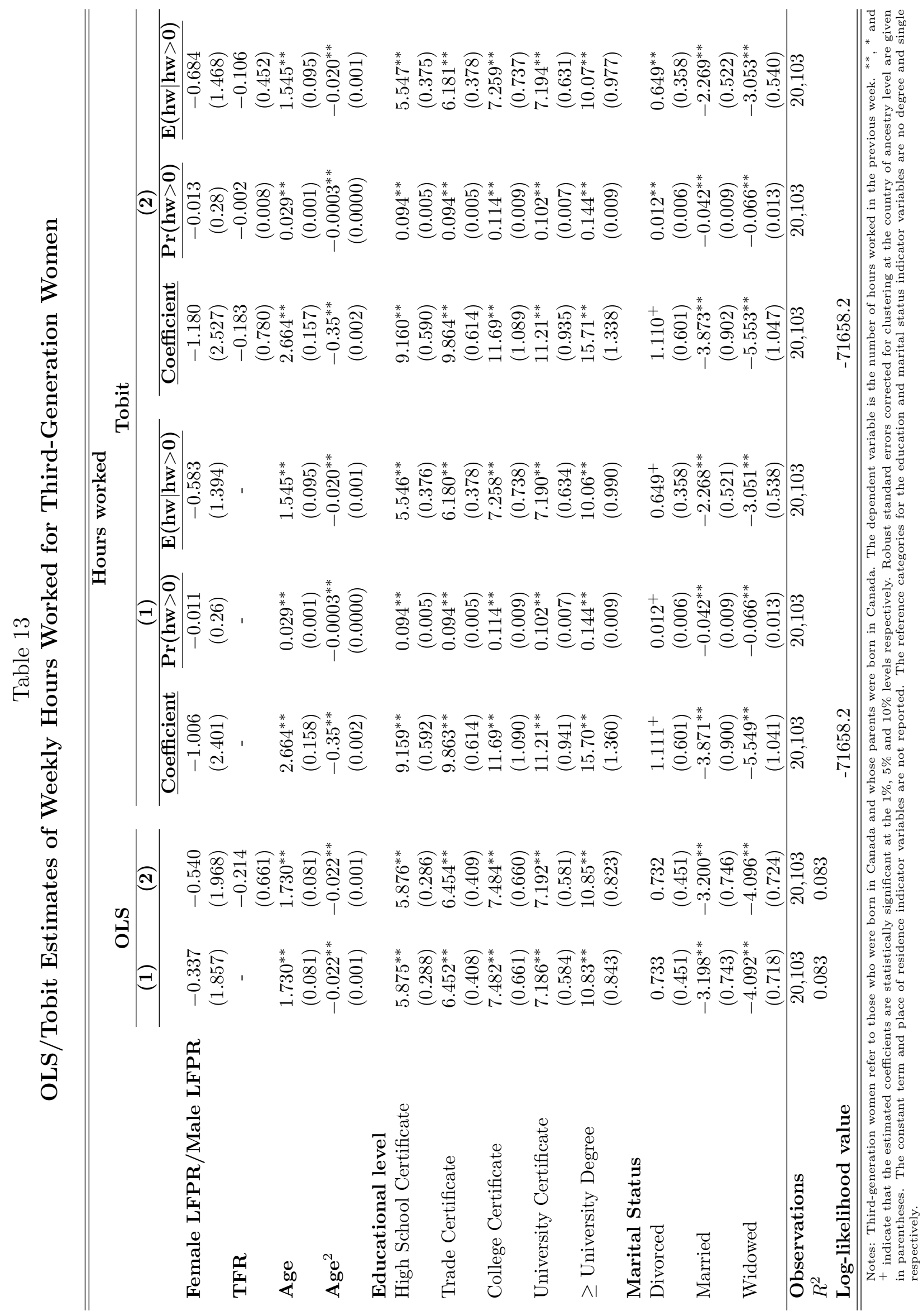

